\title{
The impact of heavy and disordered use of games and social media on adolescents' psychological, social, and school functioning
}

\author{
REGINA VAN DEN EIJNDEN*, INA KONING, SUZAN DOORNWAARD, FEMKE VAN GURP and TOM TER BOGT
}

Department of Interdisciplinary Social Sciences, Utrecht University, Utrecht, The Netherlands

(Received: January 11, 2018; revised manuscript received: July 1, 2018; accepted: July 29, 2018)

\begin{abstract}
Aim: To extend the scholarly debate on (a) whether or not the compulsive use of games and social media should be regarded as behavioral addictions (Kardefelt-Winther et al., 2017) and (b) whether the nine DSM-5 criteria for Internet gaming disorder (IGD; American Psychiatric Association [APA], 2013) are appropriate to distinguish highly engaged, non-disordered users of games and social media from disordered users, this study investigated the impact of engaged and disordered use of games and social media on the psychosocial well-being and school performances of adolescents. Methods: As part of the Digital Youth Project of the University of Utrecht, a three-wave longitudinal sample of 12- to 15 -year-old adolescents $(N=538)$ was utilized. Three annual online measurements were administered in the classroom setting, including IGD, social media disorder, life satisfaction, and perceived social competence. Schools provided information on students' grade point average. Results: The symptoms of disordered use of games and social media showed to have a negative effect on adolescent's life satisfaction, and the symptoms of disordered gaming showed a negative impact on adolescents' perceived social competence. On the other hand, heavy use of games and social media predicted positive effects on adolescents' perceived social competence. However, the heavy use of social media also predicted a decrease in school performances. Several gender differences in these outcomes are discussed. Conclusion: The findings propose that symptoms of disordered use of games and social media predict a decrease in the psychosocial well-being and school performances of adolescents, thereby meeting one of the core criteria of behavioral addictions.
\end{abstract}

Keywords: game addiction, social media addiction, psychosocial well-being, school functioning, adolescents, consequences

\section{INTRODUCTION}

Intensive gaming and social media use have frequently been linked to the development of addictive-like behaviors among adolescents (Griffiths, Kuss, \& Demetrovics, 2014; Lemmens, Valkenburg, \& Gentile, 2015; Van den Eijnden, Lemmens, \& Valkenburg, 2016; Van Rooij, Schoenmakers, Van den Eijnden, \& Van de Mheen, 2010). Although there is an ongoing debate on the conceptualization and measurement of addictive use of games (e.g., De Cock et al., 2014; Festl, Scharkow, \& Quandt, 2013; Griffiths, King, \& Demetrovics, 2014), Internet gaming disorder (IGD) has been included in section III of the fifth edition of the Diagnostic and Statistical Manual of Mental Disorders (DSM-5; American Psychiatric Association [APA], 2013), and gaming disorder has recently received an official status as mental health condition in the ICD-11 (World Health Organization, 2018). In contrast, addictive-like social media use - here referred to as social media disorder (SMD; Van den Eijnden et al., 2016) and regarded an umbrella term for addictive-like use of all social network sites (e.g., Facebook, Instagram, and Twitter) and instant messengers (e.g., WhatsApp and Snapchat) - now has no status in DSM-5 or ICD-11. An increasing body of evidence, however, suggests that both IGD and SMD are growing mental health problems, particularly among adolescents (Kuss \& Griffiths, 2011, 2012; Mentzoni et al., 2011; Pantic, 2014; Ryan, Chester, Reece, \& Xenos, 2014), with $3 \%-9 \%$ of adolescent online gamers meeting the criteria for IGD (Festl et al., 2013; Müller et al., 2015; Van Rooij, Schoenmakers, Vermulst, Van Den Eijnden, \& Van De Mheen, 2011) and 5\%-11\% of youngsters meeting the criteria for SMD (Boer \& Van den Eijnden, 2018; Van den Eijnden et al., 2016). Since adolescence is a developmental period marked by profound physical, cognitive, emotional, and social changes, IGD and SMD may have significant and enduring consequences for the psychological and social development of youngsters. It is therefore of vital importance to have a better understanding of the impact of these phenomena on adolescent development.

\section{Conceptualization of IGD and SMD}

Existing research has predominantly defined IGD on the basis of the six core criteria for substance dependence,

\footnotetext{
* Corresponding author: Regina van den Eijnden; Department of Interdisciplinary Social Sciences, Utrecht University, PO Box 80140, Utrecht 3508 TC, The Netherlands; Phone: +31 30253 7980; E-mail: R.J.J.M.vandenEijnden@uu.nl
}

This is an open-access article distributed under the terms of the Creative Commons Attribution-NonCommercial 4.0 International License, which permits unrestricted use, distribution, and reproduction in any medium for non-commercial purposes, provided the original author and source are credited, a link to the CC License is provided, and changes - if any - are indicated. 
i.e., loss of control, preoccupation, problems, tolerance, withdrawal symptoms, and coping/escapism (Brand, Laier, \& Young, 2014; Kuss \& Griffiths, 2011; Müller et al., 2015; Wegmann, Stodt, \& Brand, 2015). The DSM-5 definition for IGD additionally lists symptoms of deception, displacement, and conflict (Petry et al., 2014). Together, these nine criteria have been adopted by the IGD scale developed by Lemmens et al. (2015), as well as the SMD scale developed by Van den Eijnden et al. (2016). However, some researchers have warned against the use of substance addiction criteria to define Internet-related and other behavioral addictions, asserting that these criteria do not adequately distinguish disordered behavior (i.e., addicted) from highly engaged (i.e., heavy), non-disordered behavior (Deleuze et al., 2017; Kardefelt-Winther et al., 2017). In an attempt to elucidate what is fundamental for the characterization of behavioral addictions, Kardefelt-Winther et al. (2017, p. 2) had proposed to define it as "repeated behavior leading to significant harm or distress of a functionally impairing nature, which is not reduced by the person and persists over a significant period of time." Thus, to determine whether IGD and SMD should be regarded as behavioral addictions, insight into whether symptoms of IGD and SMD predict significant impairments in adolescents' psychosocial and school functioning over time is urgently needed.

\section{Negative consequences of IGD and SMD}

In cross-sectional studies, problematic gaming has been linked to a range of negative outcomes, such as lower school grades (Chiu, Lee, \& Huang, 2004; Gentile, 2009; Kuss \& Griffiths, 2012; Müller et al., 2015; Skoric, Teo, \& Neo, 2009), depression and low self-esteem (Männikkö, Billieux, \& Kääriäinen, 2015; Mentzoni et al., 2011; Müller et al., 2015; Van Rooij, Ferguson, Van de Mheen, \& Schoenmakers, 2015), and low life satisfaction (Festl et al., 2013; Lemmens et al., 2015; Mentzoni et al., 2011; Subramaniam et al., 2016). Other studies have found problematic gaming to be related to social problems, such as loneliness and decreased social competence (Kuss \& Griffiths, 2011; Lemmens et al., 2015; Müller et al., 2015). However, only a handful of studies have utilized the longitudinal design that is required to gain more insight into the order of events, and these studies generated inconclusive results regarding the effects of IGD. Gentile et al. (2011) found that the pathological video game use among Singaporean adolescents predicted poorer school grades and lower psychological well-being 2 years later. In contrast, Ferguson and Ceranoglu (2014) found no effect of pathological gaming on grade point average (GPA) scores 1 year later. Lemmens, Valkenburg, and Peter (2011) and Scharkow, Festl, and Quandt (2014) did not report any longitudinal effects of IGD on life satisfaction, self-esteem, and perceived social competence, but found pathological gaming to predict increased loneliness 6 months later.

In comparison to the literature on IGD, research on the correlates of addictive-like social media use is much more limited, and longitudinal research is almost missing. In cross-sectional research, SMD (including Facebook, social network site, and instant messaging addiction) has been related to lower life satisfaction (Satici \& Uysal, 2015), lower psychological well-being (De Cock et al., 2014; Hong, Huang, Lin, \& Chiu, 2014; Koc \& Gulyagci, 2013; Van den Eijnden et al., 2016; Wang, Gaskin, Wang, \& Liu, 2016), more loneliness (De Cock et al., 2014; Van den Eijnden et al., 2016; Yu, Wu, \& Pesigan, 2015), lower levels of social competence (Satici, Saricali, Satici, \& Çapan, 2014), and negative learning outcomes (Aladwani \& Almarzouq, 2016; Huang \& Leung, 2009). However, due to the absence of longitudinal studies, we do not know whether these correlates are predictors or outcomes of SMD. The only longitudinal study that we are aware of showed that time spent on Facebook directly predicted a decrease in self-reported academic performance 6 months later, whereas Facebook addiction alone indirectly affected the perceived academic performance through decreased academic motivation (Wohn \& LaRose, 2014).

\section{The present study}

To summarize, although cross-sectional studies suggest that SMD may impact adolescents' psychosocial well-being and school functioning, longitudinal research addressing SMD as an umbrella concept is missing. Moreover, the current state of the art shows inconclusive findings with regard to the longitudinal consequences of IGD. Therefore, the current three-wave longitudinal study, with 1-year interval periods, aims to contribute to the existing knowledge by examining whether IGD and SMD predict a decline in life satisfaction, perceived social competence, and learning outcomes (i.e., GPA) over time among adolescents aged 12-15 years. To contribute to the discussion of whether IGD and SMD should be regarded as behavioral addictions (Kardefelt-Winther et al., 2017) and whether the current IGD and SMD criteria adequately distinguish highly engaged (i.e., heavy), non-disordered users of games and social media from disordered (i.e., addicted) users, we will test the outcomes of intensities of both game and social media use as well as the symptoms of IGD and SMD. Finally, since boys and girls differ in their use of online applications, with boys being more involved in gaming and more likely to develop symptoms of disordered gaming (Chiu et al., 2004; Gentile, 2009; Lemmens et al., 2011; Mentzoni et al., 2011) and girls being more attracted to social media use (e.g., Kuss \& Griffiths, 2011; Lenhart et al., 2015), we will explore whether gender moderates the impact of intensity of games and social media use and symptoms of IGD and SMD on adolescents' life satisfaction, perceived social competence, and GPA.

\section{METHODS}

\section{Sample}

The data were derived from the Digital Youth Project, an ongoing longitudinal study at Utrecht University. Data were collected through online self-report questionnaires administered in the classroom setting using Qualtrics survey software. For this study, students in the 7 th and 8th grades (at $\mathrm{T}_{1}$ ) of two schools for secondary education were followed 
for 2 years with annual assessments from February to March $2015\left(\mathrm{~T}_{1}\right), 2016\left(\mathrm{~T}_{2}\right)$, and $2017\left(\mathrm{~T}_{3}\right)$. The final sample consisted of 543 adolescents with ages ranging from 12 to 15 years $\left(M_{\text {age }}=12.9, S D=0.73\right)$ at $\mathrm{T}_{1}$, of whom five repeated class at $\mathrm{T}_{2}$ or $\mathrm{T}_{3}$. As repeating a class may influence school grades, these adolescents were excluded from the analyses. This resulted in a sample of 538 adolescents eligible for analyses. Gender was evenly distributed (51.1\% girls) and most adolescents had a Dutch ethnic background (96.5\%). Students were in lower level vocational education $(4.6 \%)$, moderate level secondary education $(47.8 \%)$, and high school or preuniversity education $(47.6 \%)$.

\section{Measures}

Gaming hours per week was measured using two items asking for the number of days playing games per week (0-7 days per week) and the duration of playing ( $0-9 \mathrm{hr}$ or more per day). The two items were multiplied. Five respondents were indicated as outliers and their scores were recoded into mean score $+2 S D$.

IGD symptoms were measured using nine dichotomous $(1=\mathrm{no} / 2=$ yes $)$ items of the IGD scale (Lemmens et al., 2015), which were based on the diagnostic criteria of IGD, i.e., Preoccupation, Persistence, Tolerance, Withdrawal, Displacement, Escape, Problems, Deception, and Conflict, as described in the Appendix of the DSM-5. A sample item measuring Persistence is, "During the last 12 months .... were you unable to reduce your time playing games after others had repeatedly told you to play less?" A sum score of the nine items was calculated. Cronbach's $\alpha$ values were .73 $\left(\mathrm{T}_{1}\right)$ and $.76\left(\mathrm{~T}_{2}\right)$.

Frequency of social media use was measured using six items. Prior to these questions, a definition of social media use was given: "The term social media refers to social network sites (e.g., Facebook, Instagram, and Twitter), and instant messengers (e.g., WhatsApp, Snapchat, and Facebook messenger)." Four items reflected the use of social networking sites (e.g., "How many times a day do you check your social network sites?") and two items reflected instant messaging through smartphone (e.g., "How many times a day do you send a message, picture, or video with your smartphone?") using a 7-point response scale [ranging from 0 (less than once a day/week) to 7 (more than 40 times a day/week)]. An average score of the six items was calculated. Cronbach's $\alpha$ value was .87 at $\mathrm{T}_{1}$ and $\mathrm{T}_{2}$.

SMD symptoms were measured using nine dichotomous (yes/no) items of the SMD scale (Van den Eijnden et al., 2016). These nine items measured the same nine criteria that were used to measure IGD, but then were applied to social media use. Adolescents were, for instance, asked "During the past year, have you .... regularly neglected other activities (e.g., hobbies and sport) because you wanted to use social media?" A sum score was calculated. Cronbach's $\alpha$ values were $.67\left(\mathrm{~T}_{1}\right)$ and $.73\left(\mathrm{~T}_{2}\right)$.

Perceived social competence was assessed using the 5item Dutch version of the Harters' Self Perception Profile of Adolescents (Harter, 1988; Treffers et al., 2002). We used the subscale "Close Friendships" for assessing the ability to establish and retain close friendships, using a 6-point answer scale ranging from 1 (totally agree) to 6 (totally disagree). An example of an item is "I find it hard to get friends on whom I can count." Items were recoded so that the mean score indicated a higher level of perceived social competence. Cronbach's $\alpha$ values ranged from $.67\left(\mathrm{~T}_{1}\right.$ and $\left.\mathrm{T}_{3}\right)$ to $.77\left(\mathrm{~T}_{2}\right)$.

Life satisfaction was measured with the 5-item Satisfaction with Life Scale developed by Diener, Emmons, Larsen, and Griffin (1985) and two additional items. An example of an item is "I am satisfied with my life." Response categories ranged from 1 (totally agree) to 6 (totally disagree). A mean score was calculated. Cronbach's $\alpha$ values ranged from .81 to .86 .

GPA was calculated on the basis of the school grades that were provided by the schools. GPA was computed as the average grade of the six most important courses and ranged from 0 to 10 .

Level of education was divided into low to moderate education (lower vocational training or moderate level secondary education; 52.4\%) and higher education (lower vocational training or moderate level secondary education; $52.4 \%)$.

\section{Strategy for analysis}

Of the 538 participants, there were 293 (54.1\%) complete cases in which individuals participated in all three measurement occasions and 493 (90.9\%) individuals participated in at least two measurement occasions. While Little's Missing Completely at Random Test (Little, 1988) was significant, $\chi^{2}(289)=405.70, p<.001$, a normed $\chi^{2}\left(\chi^{2} / d f\right)$ value of 1.40 was identified, indicating a good fit between the sample scores with and without imputation (Bollen, 1989). Missing data were estimated in Mplus using the Full Information Maximum Likelihood with Robust Standard Errors default setting, allowing information of all the 538 participants to be used for analysis (Muthén \& Muthén, 1998-2012; Werner, 2000).

Descriptive statistics and correlations were retrieved for the total group, for boys and girls separately, and for each measurement occasion. We used structural equation modeling to test two models: one model with game hours per week and IGD symptoms and other model with frequency of social media use and SMD symptoms as predictors (combined models). In both models, the two predictors were regressed upon three outcome variables, i.e., life satisfaction, perceived social competence, and GPA. The direct effects were examined for the predictor variables at $T_{1}$ on the subsequent outcome variables at $T_{2}$ and at $T_{2}$ on the subsequent outcome variables at $T_{3}$. In each of the models, the outcome variable at the previous measurement was included as a control variable, as well as level of education and gender. In line with Nieminen, Lehtiniemi, Vähäkangas, Huusko, and Rautio (2013), we used the standardized $\beta \mathrm{s}$ as effect size indices, whereby $\beta<0.2$ was considered a small, $0.2<\beta<0.5$ a moderate, and $\beta>0.5$ a strong effect. Then, the interaction terms between the predictor variables and gender were added to the models. Due to missing data, adding these interaction terms resulted in a lower sample size for the analyses from $\mathrm{T}_{2}$ to $\mathrm{T}_{3}(n=366)$. 
Perceived social competence, life satisfaction, and GPA were all negatively skewed at all time points. Thus, bootstrapping was used to generate random samples (500) based on the original data to account for non-normality, and $95 \%$ confidence intervals were based on the bootstrap corrected estimates of direct effects (Geiser, 2013; Selig \& Preacher, 2009). Goodness of model fit was evaluated using the comparative fit index (CFI) and the root mean square error of approximation (RMSEA). Standard criteria were used to assess acceptable model fit indices wherein CFI should be 0.90 or higher and RMSEA should be 0.08 or below (Geiser, 2013).

\section{Ethics}

The study procedures were carried out in accordance with the Declaration of Helsinki and were approved by the board of ethics of the Faculty of Social Sciences at Utrecht University (FETC16-076 Eijnden). All participants and their parents were fully informed about the study and were granted the right to refuse to participate before the study began or at any juncture of the data.

\section{RESULTS}

\section{Descriptive statistics}

Descriptive statistics were calculated across measurement occasions for the total group and boys and girls separately (Table 1). Girls reported fewer game hours $\left(\mathrm{T}_{1}: t=-12.35\right.$, $\left.p<.001 ; \mathrm{T}_{2}: t=-7.89, p<.001\right)$ and IGD symptoms $\left(\mathrm{T}_{1}\right.$ : $\left.t=-7.49, p<.001 ; \mathrm{T}_{2}: t=-4.14, p<.001\right)$ compared to boys. Girls use social media somewhat more frequently $\left(\mathrm{T}_{1}\right.$ : $\left.t=3.62, p<.001 ; \mathrm{T}_{2}: t=3.58, p<.001\right)$, experience a higher perceived social competence $\left(\mathrm{T}_{1}: t=3.49, p<.001 ; \mathrm{T}_{2}\right.$ : $t=3.48, p<.001)$, and have a higher GPA $\left(\mathrm{T}_{1}: t=4.72\right.$, $\left.p<.001 ; \mathrm{T}_{2}: t=2.74, p<.05\right)$ than boys. No gender differences were found in SMD symptoms and life satisfaction.
Correlations between all constructs that were measured at different time points can be found in Table 2 (separately for girls and boys). The overall pattern is that IGD is negatively related to the perceived social competence and life satisfaction of both boys and girls (for almost all measurements) and that SMD is negatively related to the life satisfaction of girls (all measurements) and boys at $T_{2}$. In addition, SMD is negatively related to the GPA at $\mathrm{T}_{2}$ for girls, but not to the GPA for boys. Moreover, the frequency of social media use is negatively related to the GPA of boys at $T_{2}$ and $T_{3}$ and of girls at $T_{2}$ and to the perceived life satisfaction of boys (almost all measurements), but not that of girls. Finally, one positive correlation was found, namely between frequency of social media use at $\mathrm{T}_{2}$ and perceived social competence of girls at $\mathrm{T}_{3}$.

\section{Gaming hours and IGD symptoms}

The model testing the effect of gaming hours and IGD showed an acceptable model fit $(\mathrm{CFI}=0.88$, RMSEA $=$ 0.07). However, no significant main effects of hours gaming per week on school grades and life satisfaction, were found (Table 3). Instead, there was a small positive effect of gaming hours $T_{1}$ on perceived social competence $T_{2}$, suggesting that the intensity of gaming predicted an increase in perceived social competence 1 year later.

IGD symptoms at $T_{1}$ showed to have a small effect on life satisfaction $\mathrm{T}_{2}(\beta=-0.17, p<.05)$ and this effect was marginally significant from $\mathrm{T}_{2}$ to $\mathrm{T}_{3}(\beta=-0.16, p=.08$; Table 3$)$. In addition, IGD symptoms showed to have a moderate negative effect on subsequent perceived social competence $\left(\mathrm{T}_{2}: \beta=-0.22, p<.001 ; \mathrm{T}_{3}: \beta=-0.29\right.$, $p<.001)$. There was no effect found on GPA.

Two interaction effects with gender were found. Gender showed to moderate the effect of IGD symptoms $\mathrm{T}_{2}$ on both life satisfaction $\mathrm{T}_{3}(\beta=0.56, p<.01)$ and social competence $\mathrm{T}_{3}(\beta=0.56, p<.05)$. As shown in Figure 1 , the negative effects of IGD symptoms on life satisfaction and perceived social competence were significant only for boys, and not for girls.

Table 1. Descriptive statistics at each time point for the total group and separately for girls and boys

\begin{tabular}{lccc}
\hline & & & $M(S D)$ \\
\cline { 2 - 3 } Variable & Total & Girls $(51.1 \%)$ & Boys $(48.9 \%)$ \\
\hline Age & $12.90(0.73)$ & $12.84(0.68)$ & $12.96(0.78)$ \\
Level of education (\% high) & 95.40 & 95.60 & 95.10 \\
Gaming hours $\mathrm{T}_{1}$ & $8.30(8.37)$ & $4.13(5.31)$ & $12.22(8.83)^{* *}$ \\
Gaming hours $\mathrm{T}_{2}$ & $8.02(9.29)$ & $3.75(6.54)$ & $11.42(9.76)^{* *}$ \\
Internet gaming disorder $\mathrm{T}_{1}$ & $9.79(1.42)$ & $9.32(0.96)$ & $10.23(1.63)^{* *}$ \\
Internet gaming disorder $\mathrm{T}_{2}$ & $9.73(1.43)$ & $9.36(0.99)$ & $10.02(1.65)^{* *}$ \\
Frequency of social media use $\mathrm{T}_{1}$ & $22.52(8.44)$ & $23.79(8.19)$ & $21.19(8.49)^{* *}$ \\
Frequency of social media use $\mathrm{T}_{2}$ & $22.54(7.88)$ & $23.96(7.53)$ & $21.06(7.98)^{* *}$ \\
Social media disorder $\mathrm{T}_{1}$ & $9.85(1.29)$ & $9.85(1.32)$ & $9.86(1.26)$ \\
Social media disorder $\mathrm{T}_{2}$ & $10.00(1.56)$ & $10.06(1.67)$ & $9.96(1.43)$ \\
Social competence $\mathrm{T}_{2}$ & $5.23(0.66)$ & $5.34(0.58)$ & $5.11(0.72)^{* *}$ \\
Social competence $\mathrm{T}_{3}$ & $5.23(0.67)$ & $5.33(0.59)$ & $5.09(0.74)^{* *}$ \\
Life satisfaction $\mathrm{T}_{2}$ & $4.71(0.79)$ & $4.69(0.78)$ & $4.73(0.81)$ \\
Life satisfaction $\mathrm{T}_{3}$ & $4.61(0.78)$ & $4.56(0.78)$ & $4.68(0.78)$ \\
School grade $\mathrm{T}_{2}$ & $6.74(0.74)$ & $6.91(0.75)$ & $6.55(0.67)^{* *}$ \\
School grade $\mathrm{T}_{3}$ & $6.52(0.72)$ & $6.59(0.77)$ & $6.44(0.64)^{*}$ \\
\hline
\end{tabular}

Note. The symbol "*” indicates whether boys significantly differ from girls with ${ }^{*} p<.05$ and ${ }^{* *} p<.01 . S D$ : standard deviation. 

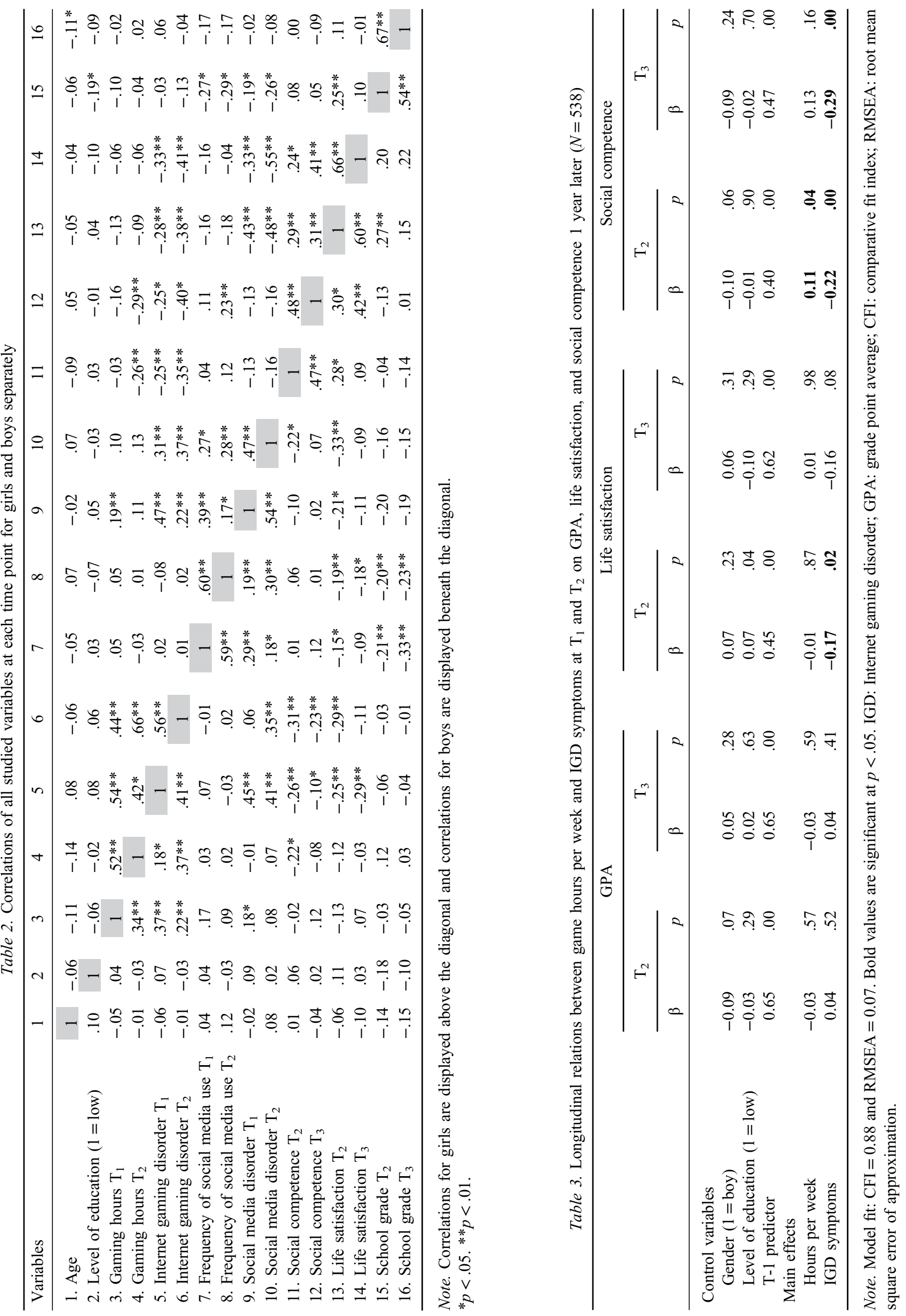

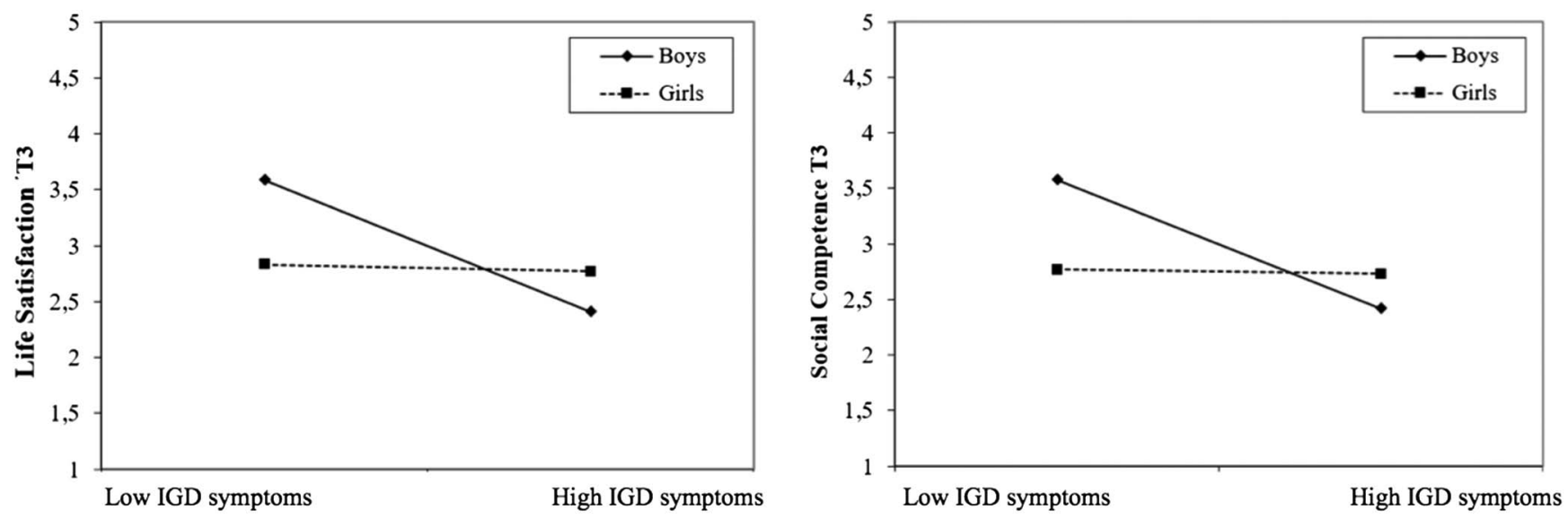

Figure 1. The effect of IGD symptoms $\mathrm{T}_{2}$ on life satisfaction $\mathrm{T}_{3}$ and perceived social competence $\mathrm{T}_{3}$ by gender

Table 4. Longitudinal relations between frequency of social media use at $\mathrm{T}_{1}$ and $\mathrm{T}_{2}$ on GPA, life satisfaction, and social competence 1 year later $(N=538)$

\begin{tabular}{|c|c|c|c|c|c|c|c|c|c|c|c|c|}
\hline & \multicolumn{4}{|c|}{ GPA } & \multicolumn{4}{|c|}{ Life satisfaction } & \multicolumn{4}{|c|}{ Social competence } \\
\hline & \multicolumn{2}{|c|}{$\mathrm{T}_{2}$} & \multicolumn{2}{|c|}{$\mathrm{T}_{3}$} & \multicolumn{2}{|c|}{$\mathrm{T}_{2}$} & \multicolumn{2}{|c|}{$\mathrm{T}_{3}$} & \multicolumn{2}{|c|}{$\mathrm{T}_{2}$} & \multicolumn{2}{|c|}{$\mathrm{T}_{3}$} \\
\hline & $\beta$ & $p$ & $\beta$ & $p$ & $\beta$ & $p$ & $\beta$ & $p$ & $\beta$ & $p$ & $\beta$ & $p$ \\
\hline \multicolumn{13}{|l|}{ Control variables } \\
\hline Sex $(1=$ boy $)$ & -0.13 & .00 & 0.04 & .31 & 0.05 & .29 & 0.05 & .42 & -0.11 & .03 & -0.08 & .23 \\
\hline Level of education $(1=$ low $)$ & -0.16 & .00 & 0.02 & .54 & 0.05 & .09 & -0.09 & .33 & 0.01 & .74 & -0.02 & .82 \\
\hline Outcome T-1 & 0.61 & .00 & 0.64 & .00 & 0.23 & .02 & 0.58 & .00 & 0.41 & .00 & 0.49 & .00 \\
\hline \multicolumn{13}{|l|}{ Main effects } \\
\hline Frequency & -0.09 & .04 & -0.05 & .26 & 0.14 & .07 & 0.09 & .13 & 0.01 & .79 & 0.14 & .03 \\
\hline SMD symptoms & -0.01 & .85 & 0.05 & .30 & -0.77 & .00 & -0.17 & .04 & -0.05 & .40 & -0.12 & .08 \\
\hline
\end{tabular}

Note. Model fit: $\mathrm{CFI}=0.90$ and RMSEA $=0.06$. Bold values are significant at $p<.05$. GPA: grade point average; CFI: comparative fit index; RMSEA: root mean square error of approximation; SMD: social media disorder.

\section{Frequency of social media use and SMD symptoms}

The model fit of the model was satisfactory $(\mathrm{CFI}=0.90$, RMSEA $=0.06$ ). There was a small negative effect of frequency of social media use (Table 4) $\mathrm{T}_{1}$ on GPA $\mathrm{T}_{2}$ $(\beta=-0.09, p<.05)$, suggesting that more frequent social media use $\mathrm{T}_{1}$ predicted a lower GPA $\mathrm{T}_{2}$. In addition, there was a small positive effect of social media use $\mathrm{T}_{2}$ on perceived social competence $\mathrm{T}_{3}(\beta=0.14, p<.05)$, indicating that more frequent social media use improved the perceived social competence after 1 year.

SMD symptoms $T_{1}$ revealed a strong negative effect on life satisfaction $\mathrm{T}_{2}(\beta=-0.77, p<.001)$ and SMD symptoms $\mathrm{T}_{2}$ also had a similar - although smaller - effect on life satisfaction $\mathrm{T}_{3}(\beta=-0.17, p<.05$; Table 4$)$. Thus, more SMD symptoms predicted a lower level of life satisfaction 1 year later.

Three significant interaction effects with gender were found. Gender moderated the effect of SMD symptoms on life satisfaction $\mathrm{T}_{2}(\beta=0.44, p<.01)$ and $\mathrm{T}_{3}(\beta=0.49$, $p<.001)$. As shown in Figure 2, the negative effect of SMD symptoms on life satisfaction was stronger for boys than for girls. Finally, SMD symptoms $\mathrm{T}_{2}$ predicted a decrease in GPA at $\mathrm{T}_{3}$ for girls, but not for boys $(\beta=-0.38, p<.05$; Figure 2$)$.

\section{DISCUSSION}

The present longitudinal study with three annual measurement waves is one of the first studies investigating the outcomes of engaged (i.e., heavy) and disordered (i.e., addicted) gaming and social media use of young adolescents. In general, heavy gaming and social media use do not appear to have negative effects on the psychosocial well-being of adolescents. On the contrary, some positive effects are found, suggesting that frequent engagement in either gaming or social media use can be helpful in developing and maintaining social relations and friendships. In contrast, symptoms of disordered engagement in gaming and social media use seem to decrease the psychosocial well-being, with symptoms of disordered gaming (IGD) having small to moderate negative effects on life satisfaction and perceived social competence and symptoms of disordered social media use (SMD) having strong negative effects on life satisfaction. All these negative outcomes generally appear to be stronger in boys than in girls. With regard to school performances, the findings show a small negative effect of heavy social media use on adolescents' GPA and an additional negative effect of symptoms of SMD only for girls. 

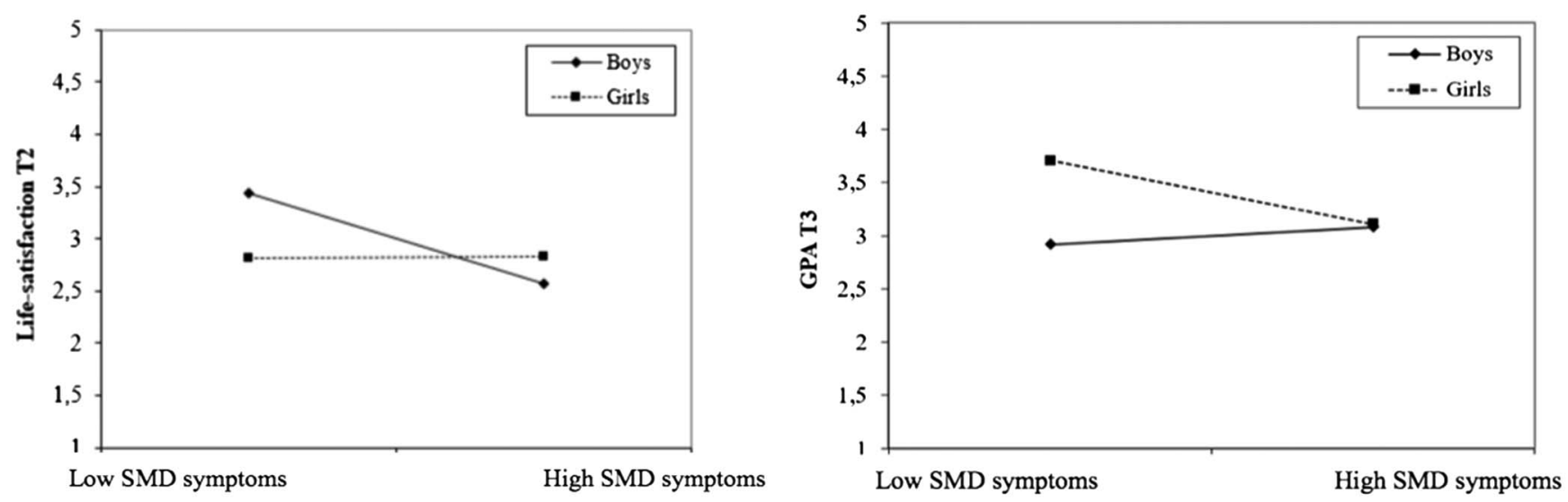

Figure 2. The effect of SMD symptoms $\mathrm{T}_{1}$ on life satisfaction $\mathrm{T}_{2}$ and SMD symptoms $\mathrm{T}_{2}$ on GPA $\mathrm{T}_{3}$ by gender

\section{Outcomes of IGD symptoms and intensity of game use}

The findings of this study imply that symptoms of IGD negatively impact the psychological and social functioning of adolescents, whereas these effects are absent for heavy (engaged) gaming. On the contrary, engaged gaming may even generate a positive effect on perceived social competence. These findings are relevant for the scholarly discussion about whether IGD should be regarded as a behavioral addiction and whether the nine DSM-5 criteria for IGD (APA, 2013) are appropriate to differentiate between highly engaged and disordered users of games. In general, our findings confirm that it is not the frequency of gaming as such, but disordered gaming as assessed by the IGD scale that is responsible for negative outcomes. In addition, boys appear to be more sensitive to these negative effects, with negative outcomes of IGD symptoms being stronger in boys than in girls.

Our results are only partly in line with earlier studies. The findings of this study seem to contradict previous zerofindings with regard to life satisfaction and perceived social competence found by Lemmens et al. (2011). These authors, however, found a significant longitudinal effect of IGD on loneliness, a concept that is closely related to the perceived social competence. Moreover, in contrast with the study by Gentile et al. (2011), we did not find any evidence that frequent gaming or IGD symptoms negatively affected the adolescents' school performances. These inconsistent findings may relate to the fact that this study used school-reported GPA, whereas Gentile et al. relied on self-reported measures, which may have been affected by adolescent's subjective experience of school performances.

Boys appear to be more vulnerable to negative effects of disordered gaming than girls. This result may be understood in the light of the fact that IGD symptoms are much less common in girls. Thus, the absence of effects in girls may be related to the lower prevalence of IGD symptoms in them, and thus to the lower statistical power. This gender difference, however, might also be related to the different games that boys and girls are playing, i.e., male gamers seem to be drawn more to games from the Strategy, Role Playing, Action, and Fighting genres, whereas female gamers are more likely to be drawn to games from the Social, Puzzle/Card, Music/Dance, Educational/
Edutainment, and Simulation genres (Phan, Jardina, Hoyle, $\&$ Chaparro, 2012). The game genres preferred by boys may have a higher addictive potential. Future research should further address these gender differences and the role of preferred game genres.

To the best of authors' knowledge, this is the first study displaying that IGD symptoms have a negative influence on adolescents' life satisfaction and perceived social competence, particularly in boys. In addition, previous data indicated that lowered levels of perceived social competence increase the risk of developing pathological gaming (Peeters, Koning, \& Van den Eijnden, 2018), suggesting a negative downward spiral whereby socially vulnerable adolescents may become more susceptible to developing symptoms of IGD, which in turn seem to harm social functioning and relationships with peers. Further research should also focus on gender differences, as this spiral seems to pertain much more to boys than to girls.

\section{Outcomes of SMD symptoms and intensity of social media use}

As with gaming, the findings of this study indicate that engaged social media use has a positive effect on perceived social competence, indicating that social media use may help adolescents in maintaining their social relationships. In contrast, the results imply that disordered social media use has a negative impact on adolescents' life satisfaction. This finding is noteworthy and implies that SMD symptoms may lead to significant psychological harm, thereby meeting one of the core criteria of a behavioral addiction. Remarkable enough, as for IGD symptoms, this negative effect of SMD symptoms on life satisfaction is higher in boys than in girls. Since there is no gender difference in SMD symptoms, and we know very little about gender differences in social media use preferences, we can only speculate about possible explanations. Future research has to address this gap in the literature.

With regard to school performances, the findings of this study suggest that engaged use of social media seems to have a small adverse effect on GPA. In addition, there is some evidence that SMD symptoms negatively impact the GPA of girls only. These findings are in line with the longitudinal study by Wohn and LaRose (2014) showing 
that time spent on Facebook as well as addictive-like use of Facebook predicted a decrease in perceived academic performance, although the latter only showed an indirect effect through academic motivation. Although the size of these effects was small (Cohen, 1969), these outcomes should be taken seriously. Particularly because the small effect size may have resulted from the fact that the negative impact on school performances is more pronounced among certain subgroups of adolescents, e.g., adolescents with attentiondeficit hyperactivity disorder, since they are more likely to be distracted by social media. Future research should address whether certain dispositional factors moderate the impact of engaged and disordered use of social media on school outcomes. Moreover, there is a need for research aiming at the mechanisms through which social media use may influence school performances. For instance, late-night social media use seems to affect the quality of sleep (Wolniczak et al., 2013) and may thereby negatively impact the school performances of youngsters.

\section{Strengths and limitations}

This study has important strengths, for instance, the longitudinal design with three annual measurements, the rigorous statistical tests that controlled for previous levels of engaged and disordered use of games and social media, and the inclusion of GPA as reported by the school. However, the findings should be interpreted in the light of several limitations as well, such as the fact that students from lower education levels (e.g., vocational training) were underrepresented in this sample. In addition, we had to rely on selfreports of social media and game use, since we were not able to verify these self-reports by tracking measures. In this regard, we also have to note that the age restriction of most social network sites (e.g., Facebook and Instagram) in the Netherlands is 13 years old. Because our sample was 12-15 years old at $T_{1}$, we checked whether these age restrictions might have influenced the reported use of social network sites. This, however, did not seem to be the case (i.e., 93\% of both 12- and 13-year-old participants reported to use social network sites). Then, the model fit indices were satisfactory but not excellent, and several of the reported findings showed small effect sizes. However, with regard to the latter, we would like to refer to the rigorous statistical tests that were conducted, i.e., longitudinal models controlling for previous levels of the dependent variables as well as for demographic characteristics. Because of these strict tests, we believe that even the small effects that were found can be meaningful. Finally, we would like to note that even with the present longitudinal design we cannot rule out that a third factor, for instance, an underlying mental health problem, would be (partly) responsible for the longitudinal associations between engaged and disordered use and subsequent psychosocial and school functioning.

\section{CONCLUSIONS}

The results of this study provide important input for the debate on whether the used IGD and SMD scales (Lemmens et al., 2015; Van den Eijnden et al., 2016) that are based on the DSM-5 criteria for IGD (APA, 2013) indicate behavioral addictions with all the implied negative consequences. In their attempt to prevent overpathologizing common behaviors, Kardefelt-Winther et al. (2017) emphasized that repeated behaviors should lead to significant impairment or distress of a functionally impairing nature to be regarded as disordered behaviors. It is concluded that both symptoms of IGD and SMD, but not engaged gaming and social media use, predict negative outcomes for the psychological well-being of adolescents and that IGD symptoms, but not engaged gaming, predict negative outcomes for youngsters' social functioning. The above findings support the idea that the symptoms of disordered use of games and social media, as measured by the IGD and SMD scales, should be regarded as developmental threats for young people, thereby supporting the assumption that disordered use of games and social media should be regarded behavioral addictions.

Funding sources: No financial support was received for this project.

Authors' contribution: RvdE was responsible for the study concept and design. RvdE and FvG were responsible for data collection. IK and RvdE were responsible for data analyses and interpretation. RvdE, IK, SD, and TTB contributed to the final version of the manuscript.

Conflict of interest: The authors declare no conflict of interest.

\section{REFERENCES}

Aladwani, A. M., \& Almarzouq, M. (2016). Understanding compulsive social media use: The premise of complementing selfconceptions mismatch with technology. Computers in Human Behavior, 60, 575-581. doi:10.1016/j.chb.2016.02.098

American Psychiatric Association [APA]. (2013). Diagnostic and statistical manual of mental disorders (5th ed.). Washington, DC: APA.

Boer, M., \& Van den Eijnden, R. J. J. M. (2018). Hoofdstuk 8: Sociale media en Gamen [Chapter 8: Social media and gaming]. In G. W. J. M. Stevens, S. A. F. M. Van Dorsselaer, M. Boer, S. A. De Roos, E. L. Duinhof, T. F. M. Ter Bogt, R. J. J. M. Van den Eijnden, L. Kuyper, D. Visser, W. A. M. Vollebergh, \& M. De Looze (Eds.), HBSC 2017: Gezondheid, welzijn en de sociale context van jongeren in Nederland [HBSC 2017: Health, well-being and the social context of Dutch Youth]. Utrecht, The Netherlands: University of Utrecht.

Bollen, K. A. (1989). Structural equations with latent variables. New York, NY: John Wiley \& Sons.

Brand, M., Laier, C., \& Young, K. S. (2014). Internet addiction: Coping styles, expectancies, and treatment implications. Frontiers in Psychology, 5, 1256. doi:10.3389/fpsyg.2014.01256

Chiu, S. I., Lee, J. Z., \& Huang, D. H. (2004). Video game addiction in children and teenagers in Taiwan. CyberPsychology \& Behavior, 7(5), 571-581. doi:10.1089/cpb.2004.7.571 
Cohen, J. (1969). Statistical power analysis for the behavioral sciences. New York, NY: Academic Press.

De Cock, R. D., Vangeel, J., Klein, A., Minotte, P., Rosas, O., \& Meerkerk, G. (2014). Compulsive use of social networking sites in Belgium: Prevalence, profile, and the role of attitude toward work and school. Cyberpsychology, Behavior, and Social Networking, 17(3), 166-171. doi:10.1089/cyber. 2013.0029

Deleuze, J., Nuyens, F., Rochat, L., Rothen, S., Maurage, P., \& Billieux, J. (2017). Established risk factors for addiction fail to discriminate between healthy gamers and gamers endorsing DSM-5 Internet gaming disorder. Journal of Behavioral Addictions, 6(4), 516-524. doi:10.1556/2006.6.2017.074

Diener, E., Emmons, R. A., Larsen, R. J., \& Griffin, S. (1985). The satisfaction with life scale. Journal of Personality Assessment, 49(1), 71-75. doi:10.1207/s15327752jpa4901_13

Ferguson, C. J., \& Ceranoglu, T. A. (2014). Attention problems and pathological gaming: Resolving the 'chicken and egg' in a prospective analysis. Psychiatric Quarterly, 85(1), 103-110. doi:10.1007/s11126-013-9276-0

Festl, R., Scharkow, M., \& Quandt, T. (2013). Problematic computer game use among adolescents, younger and older adults. Addiction, 108(3), 592-599. doi:10.1111/add.12016

Geiser, C. (2013). Data analysis with Mplus. New York, NY: Guilford.

Gentile, D. (2009). Pathological video-game use among youth ages 8 to 18: A national study. Psychological Science, 20(5), 594-602. doi:10.1111/j.1467-9280.2009.02340.x

Gentile, D., Choo, H., Liau, A., Sim, T., Li, D., Fung, D., \& Khoo, A. (2011). Pathological video game use among youths: A two-year longitudinal study. Pediatrics, 127(2), e319-e329. doi:10.1542/peds.2010-1353

Griffiths, M. D., King, D. L., \& Demetrovics, Z. (2014). DSM-5 Internet gaming disorder needs a unified approach to assessment. Neuropsychiatry, 4(1), 1-4. doi:10.2217/npy.13.82

Griffiths, M. D., Kuss, D. J., \& Demetrovics, Z. (2014). Social networking addiction: An overview of preliminary findings. In K. P. Rosenberg \& L. Curtiss Feder (Eds.), Behavioral addictions. Criteria, evidence, and treatment (pp. 119-141). New York, NY: Elsevier.

Harter, S. (1988). Manual for the self-perception profile for adolescents. Denver, CO: University of Denver.

Hong, F., Huang, D., Lin, H., \& Chiu, S. (2014). Analysis of the psychological traits, Facebook usage, and Facebook addiction model of Taiwanese university students. Telematics and Informatics, 31(4), 597-606. doi:10.1016/j.tele.2014. 01.001

Huang, H., \& Leung, L. (2009). Instant messaging addiction among teenagers in China: Shyness, alienation, and academic performance decrement. CyberPsychology \& Behavior, 12(6), 675-679. doi:10.1089/cpb.2009.0060

Kardefelt-Winther, D., Heeren, A., Schimmenti, A., Van Rooij, A., Maurage, P., Carras, M., Edman, J., Blaszczynski, A., Khazaal, Y., \& Billieux, J. (2017). How can we conceptualize behavioural addiction without pathologizing common behaviours? Addiction, 112(10), 1709-1715. doi:10.1111/add.13763

Koc, M., \& Gulyagci, S. (2013). Facebook addiction among Turkish college students: The role of psychological health, demographic, and usage characteristics. Cyberpsychology, Behavior, and Social Networking, 16(4), 279-284. doi:10.1089/ cyber.2012.0249
Kuss, D. J., \& Griffiths, M. D. (2011). Online social networking and addiction - A review of the psychological literature. International Journal of Environmental Research and Public Health, 8(9), 3528-3552. doi:10.3390/ijerph8093528

Kuss, D. J., \& Griffiths, M. D. (2012). Internet gaming addiction: A systematic review of empirical research. International Journal of Mental Health and Addiction, 10(2), 278-296. doi:10.1007/ s11469-011-9318-5

Lemmens, J. S., Valkenburg, P. M., \& Gentile, D. A. (2015). The Internet Gaming Disorder Scale. Psychological Assessment, 27(2), 567-582. doi:10.1037/pas0000062

Lemmens, J. S., Valkenburg, P. M., \& Peter, J. (2011). Psychosocial causes and consequences of pathological gaming. Computers in Human Behavior, 27(1), 144-152. doi:10.1016/j. chb.2010.07.015

Lenhart, A., Duggan, M., Perrin, A., Stepler, R., Rainie, L., \& Parker, K. (2015). Teens, social media \& technology overview 2015. Washington, DC: Pew Research Center.

Little, R. J. (1988). A test of missing completely at random for multivariate data with missing values. Journal of the American statistical Association, 83(404), 1198-1202. doi:10.2307/ 2290157

Männikkö, N., Billieux, J., \& Kääriäinen, M. (2015). Problematic digital gaming behavior and its relation to the psychological, social and physical health of Finnish adolescents and young adults. Journal of Behavioral Addictions, 4(4), 281-288. doi:10.1556/2006.4.2015.040

Mentzoni, R. A., Brunborg, G. S., Molde, H., Myrseth, H., Skouverøe, K. J., Hetland, J., \& Pallesen, S. (2011). Problematic video game use: Estimated prevalence and associations with mental and physical health. Cyberpsychology, Behavior, and Social Networking, 14(10), 591-596. doi:10.1089/cyber. 2010.0260

Müller, K. W., Janikian, M., Dreier, M., Wölfling, K., Beutel, M. E., Tzavara, C., Richardson, C., \& Tsitsika, A. (2015). Regular gaming behavior and Internet gaming disorder in European adolescents: Results from a cross-national representative survey of prevalence, predictors, and psychopathological correlates. European Child \& Adolescent Psychiatry, 24(5), 565-574. doi:10.1007/s00787-0140611-2

Muthén, L. K., \& Muthén, B. O. (1998-2012). Mplus user's guide (7th ed.). Los Angeles, CA: Muthén \& Muthén.

Nieminen, P., Lehtiniemi, H., Vähäkangas, K., Huusko, A., \& Rautio, A. (2013). Standardised regression coefficient as an effect size index in summarising findings in epidemiological studies. Epidemiology, Biostatistics and Public Health, 10(4), e8854. doi: $10.2427 / 8854$

Pantic, I. (2014). Online social networking and mental health. Cyberpsychology, Behavior, and Social Networking, 17(10), 652-657. doi:10.1089/cyber.2014.0070

Peeters, M., Koning, I., \& Van den Eijnden, R. (2018). Predicting Internet gaming disorder symptoms in young adolescents: A one-year follow-up study. Computers in Human Behavior, 80, 255-261. doi:10.1016/j.chb.2017.11.008

Petry, N. M., Rehbein, F., Gentile, D. A., Lemmens, J. S., Rumpf, H., Moßle, T., Bischof, G., Tao, R., Fung, D. S., Borges, G., Auriacombe, M., González Ibáñez, A., Tam, P., \& O’Brien, C. P. (2014). An international consensus for assessing Internet gaming disorder using the new DSM-5 approach. Addiction, 109(9), 1399-1406. doi:10.1111/add.12457 
Phan, M. H., Jardina, J. R., Hoyle, S., \& Chaparro, B. S. (2012). Examining the role of gender in video game usage, preference, and behavior. In Proceedings of the human factors and ergonomics society annual meeting (Vol. 56, No. 1, pp. 1496-1500). Los Angeles, CA: Sage Publications.

Ryan, T., Chester, A., Reece, J., \& Xenos, S. (2014). The uses and abuses of Facebook: A review of Facebook addiction. Journal of Behavioral Addictions, 3(3), 133-148. doi:10.1556/JBA. 3.2014 .016

Satici, B., Saricali, M., Satici, S. A., \& Çapan, B. (2014). Social competence and psychological vulnerability as predictors of Facebook addiction. Studia Psychologica, 56(4), 301-308. doi:10.21909/sp.2014.04.738

Satici, S. A., \& Uysal, R. (2015). Well-being and problematic Facebook use. Computers in Human Behavior, 49, 185-190. doi:10.1016/j.chb.2015.03.005

Scharkow, M., Festl, R., \& Quandt, T. (2014). Longitudinal patterns of problematic computer game use among adolescents and adults - A 2-year panel study. Addiction, 109(11), 1910-1917. doi:10.1111/add.12662

Selig, J. P., \& Preacher, K. J. (2009). Mediation models for longitudinal data in developmental research. Research in Human Development, 6(2-3), 144-164. doi:10.1080/15427 600902911247

Skoric, M. M., Teo, L. L. C., \& Neo, R. L. (2009). Children and video games: Addiction, engagement, and scholastic achievement. CyberPsychology \& Behavior, 12(5), 567-572. doi:10. 1089/cpb.2009.0079

Subramaniam, M., Chua, B. Y., Abdin, E., Pang, S., Satghare, P., Vaingankar, J. A., \& Chong, S. A. (2016). Prevalence and correlates of Internet gaming problem among Internet users: Results from an Internet survey. Annals of the Academy of Medicine, Singapore, 45, 174-183.

Treffers, A. W., Goedhart, A. W., Veerman, J. W., Van den Bergh, B. R. H., Ackaert, L., \& De Rycke, L. (2002). Handleiding competentie belevingsschaal voor adolescenten [Manual of the Perceived Competence Scale for adolescents]. Lisse, The Netherlands: Swets Test Publishers.

Van den Eijnden, R. J. J. M., Lemmens, J. S., \& Valkenburg, P. M. (2016). The Social Media Disorder Scale. Computers in Human Behavior, 61, 478-487. doi:10.1016/j.chb.2016. 03.038

Van Rooij, A. J., Ferguson, C., Van de Mheen, D., \& Schoenmakers, T. M. (2015). Problematic Internet use: Comparing video gaming and social media use (conference abstract). Journal of Behavioral Addictions, 4, 1-62. doi:10. 13140/RG.2.1.1643.7600

Van Rooij, A. J., Schoenmakers, T. M., Van den Eijnden, R. J. J. M., \& Van de Mheen, D. (2010). Compulsive Internet use: The role of online gaming and other Internet applications. The Journal of Adolescent Health, 47(1), 51-57. doi:10.1016/j. jadohealth.2009.12.021

Van Rooij, A. J., Schoenmakers, T. M., Vermulst, A. A., Van Den Eijnden, R. J. J. M., \& Van De Mheen, D. (2011). Online video game addiction: Identification of addicted adolescent gamers. Addiction, 106(1), 205-212. doi:10.1111/j.1360-0443.2010. 03104.X

Wang, J. L., Gaskin, J., Wang, H. Z., \& Liu, D. (2016). Life satisfaction moderates the associations between motives and excessive social networking site usage. Addiction Research \& Theory, 24(6), 450-457. doi:10.3109/16066359. 2016.1160283

Wegmann, E., Stodt, B., \& Brand, M. (2015). Addictive use of social networking sites can be explained by the interaction of Internet use expectancies, Internet literacy, and psychopathological symptoms. Journal of Behavioral Addictions, 4(3), 155-162. doi:10.1556/2006.4.2015.021

Werner, W. (2000). Longitudinal and multigroup modeling with missing data. In T. D. Little, K. U. Schnabel, \& J. Baumert (Eds.), Modeling longitudinal and multilevel data: Practical issues, applied approaches, and specific examples (pp. 219-281). Mahwah, NJ: Lawrence Erlbaum Associates.

Wohn, D. Y., \& LaRose, R. (2014). Effects of loneliness and differential usage of Facebook on college adjustment of firstyear students. Computers \& Education, 76, 158-167. doi:10.1016/j.compedu.2014.03.018

Wolniczak, I., Caceres-DelAguila, J. A., Palma-Ardiles, G., Arroyo, K. J., Solís-Visscher, R., Paredes-Yauri, S., Mego-Aquije, K., \& Bernabe-Ortiz, A. (2013). Association between Facebook dependence and poor sleep quality: A study in a sample of undergraduate students in Peru. PLoS One, 8(3), e59087. doi:10.1371/journal.pone.0059087

World Health Organization. (2018). ICD-11 International Classification of Diseases for Mortality and Morbidity Statistics. Retrieved from https://icd.who.int/browse11/1-m/en\#/http://id. who.int/icd/entity/1448597234

Yu, S., Wu, A. M., \& Pesigan, I. J. (2015). Cognitive and psychosocial health risk factors of social networking addiction. International Journal of Mental Health and Addiction, 14(4), 550-564. doi:10.1007/s11469-015-9612-8 